\title{
METRÓPOLE RESSURGENTE: ECONOMIA, SOCIEDADE E URBANIZAÇÃO EM UM MUNDO INTERCONECTADO ${ }^{1}$
}

\author{
ALLEN J. SCOTT ${ }^{2}$
}

Universidade da Califórnia

\section{Continuidades e rupturas urbanas}

Um dos traços salientes da sociedade moderna é sua associação aparentemente endêmica com níveis elevados de urbanização. Essa associação não é meramente fortuita. Os sistemas econômicos modernos são constituídos por inúmeras unidades de capital e trabalho cuja eficiência coletiva e competitividade dependem profundamente de sua coalescência em aglomerados espaciais singulares (SCOTT, 1988a; STORPER, 1997). Sociedades economicamente avançadas, em resumo, reiteradamente produzem aglomerações de atividade produtiva que se cristalizam no solo na forma de assentamentos urbanos singulares. Assim, ainda que as cidades não se restrinjam a essa lógica, elas funcionam como um motor básico e ativo da reprodução continuada da vida econômica e social.

A urbanização na sociedade moderna, porém, não é um processo que opera harmonicamente, em parte em virtude do curso instável da economia nacional e internacional mais amplas, e em parte porque as cidades estão sempre suscetíveis à geração de rupturas e deseconomias

\footnotetext{
${ }^{1}$ Artigo publicado originalmente no International Journal of Urban and Regional Research, com o título Resurgent Metropolis: Economy, Society and Urbanization in an Interconnected World, Volume 32.3, September 2008, p.548-64. Disponível em http://onlinelibrary.wiley.com/doi/10.1111/ijur.2008.32.issue-3/issuetoc Tradutores: Daniel de Mello Sanfelici (Universidade de São Paulo - danielsanfelici@gmail.com) e Karen Heberle. A Revista GEOgraphia agradece a autorização concedida pelo autor para a tradução do artigo.

${ }^{2}$ Professor de Geografia e Políticas Públicas na Universidade da Califórnia, Los Angeles (UCLA). Contato: ajscott@geog.ucla.edu.
} 
internas. Por todo o período do boom do pós-guerra nos Estados Unidos e Europa Ocidental, as grandes cidades industriais floresceram alicerçadas em um sistema de produção em massa fordista, muito dinâmico, com demanda voraz por insumos diretos e indiretos e uma dependência em relação a grandes reservas locais de força de trabalho. Por volta da metade dos anos 1970 muitas das cidades que haviam mais se beneficiado desse sistema foram conduzidas ao limiar da falência, uma vez que a competição externa, os conflitos entre trabalhadores e o patronato, a estagflação, e rápidas mudanças tecnológicas na produção gradativamente corroeram a sustentabilidade econômica da antiga ordem. Como consequência, os anos 1970 e 1980 foram um período durante o qual muitos pesquisadores publicaram análises fortemente pessimistas sobre o futuro das cidades e regiões, e as noções de um declínio secular de longo prazo pairavam no ar. Entretanto, era também esse o período em que os germes de um renascimento urbano inaudito estavam sendo plantados, expressados, de um lado, por rápidas mudanças em direção a uma economia mais baseada no conhecimento em cidades primazes como Nova York, Paris e Londres, e, por outro, na emergência de novos espaços e comunidades industriais em lugares até então periféricos no mundo (SCOTT, 1998b). Mesmo com esse renascimento em curso, algumas dúvidas sobre o futuro das cidades ganhavam coro em muitos lugares, embora o diagnóstico tenha então mudado de figura em relação às perspectivas de declínio econômico que marcaram os anos 1970 e 1980. Assim, nos anos 1990, quando ganhou força uma tomada de consciência sobre as potencialidades das novas tecnologias de comunicação, proclamou-se que a distância estava, para todos os efeitos, morta, e que uma nova era de interações globais desconcentradas estava por emergir. Acreditava-se em muitos lugares, ademais, que as cidades iriam, a partir de então, perder muito de sua razão de ser (cf. CAIRNCROSS, 1997; O’BRIEN, 1992).

É, sem dúvida, inegável que as novas tecnologias de comunicação expandiram enormemente nossa capacidade de interação no espaço geográfico, mas a previsão concomitante de um declínio urbano não se confirma nos dados estatísticos, pelo menos até o momento. As evidências empíricas apontam crescentemente para a conclusão de que a intensificação da globalização e sua expressão em espaços de fluxos, tanto virtuais quanto materiais, tem contribuído de maneira geral para fomentar o crescimento e a multiplicação de cidades pelo mundo todo (cf. HALL, 2001; TAYLOR, 2005). Como assinala Cheshire (2006), as cidades exibem, no início do século XXI, fortes sintomas de ressurgimento, especialmente em comparação com os dias sombrios do declínio do regime 
fordista em meados da década de 1970. Outros acadêmicos, como Dear (2000) e Soja (2000), chegam a argumentar que as tendências atuais sugerem uma transformação qualitativa da própria natureza da urbanização e que, em paralelo com os surtos recentes de crescimento econômico urbano, uma gama de profundas transformações sociais e culturais também tem ocorrido nas cidades contemporâneas. Sem dúvida pode-se listar inúmeras exceções a essas assertivas (BEAUREGARD, 2004; MARKUSEN; SHROCK, 2006; TUROK; MYKHENKO, 2006). Não se está sugerindo aqui que toda e qualquer cidade do mundo está em ascensão, mas antes, que existe um grupo seleto de áreas metropolitanas em vias de crescimento rápido em decorrência do comando que exerce na nova economia, de sua capacidade de tirar vantagem da globalização e da revitalização seletiva de seu tecido interno de usos do solo e ambientes construídos.

$\mathrm{Na}$ discussão que segue, procurarei explorar novamente essas temáticas no contexto de um esforço para consolidar um arcabouço teórico básico para a análise urbana. A pedra angular desse exercício consiste em reafirmar o caráter fundamental da cidade enquanto um complexo de relações espaciais no contexto mais geral da sociedade capitalista. Pela mesma razão, um dos meus objetivos no presente artigo é tomar parte na profusão de argumentos e contra-argumentos que se multiplicam na literatura acadêmica sobre a noção de cidade, e sugerir uma abordagem que possa contribuir para assentar alguns desses argumentos em uma concepção geral e operacional da urbanização.

\section{A constituição sociogeográfica da cidade}

É de se supor que poucos estudiosos discordariam da noção de que a cidade é um fenômeno social singular cuja organização interna é, de uma forma ou de outra, uma expressão de forças sociais e econômicas mais amplas. Qualquer tentativa de definir a cidade em termos mais concretos, porém, quase certamente gerará discordâncias consideráveis. Um exame superficial da literatura sobre urbanização revela uma cacofonia de perspectivas e ênfases empíricas que são, em todos os casos, qualificadas de "urbanas" de uma forma ou de outra. Certos fenômenos empíricos são frequentemente classificados de urbanos por nenhuma outra razão senão que eles ocorrem no interior dos limites da cidade, e muitas vezes as cidades são simplesmente consideradas sinônimos de "sociedade moderna" como um todo. Entretanto, na busca por uma definição da problemática 
urbana não se pode concluir que, digamos, se $80 \%$ da população dos Estados Unidos vive hoje em regiões metropolitanas, as cidades então representam $80 \%$ de tudo aquilo que constitui a sociedade americana. Da mesma forma, a educação, a semiótica do automóvel, os efeitos da renda no comportamento dos eleitores, ou mesmo a identidade étnica não são, em primeira mão, questões urbanas, embora haja casos, como o segundo, nos quais podemos dizer que há uma intersecção com o processo urbano. Se desejamos esclarecer essa confusão - a fim de compreender exatamente o que está ressurgindo e porquê -, precisamos de uma problemática; ou seja, de um conjunto de conceitos mediante os quais possamos localizar uma lógica e dinâmica social que claramente circunscreva o urbano no âmbito mais abrangente da vida social como um todo, como argumentou há muito tempo Castells (1968).

Um ponto de partida elementar aqui é a observação que uma das coisas que todas as cidades modernas têm em comum é sua condição de densos sistemas polarizados ou multipolarizados de localizações e usos do solo inter-relacionados. Independente de quais outras particularidades sociais e econômicas que possam ser encontradas em qualquer caso determinado, as cidades são sempre sítios ou lugares onde muitas atividades e eventos diferentes ocorrem em grande proximidade um em relação ao outro. Eu reafirmo esse truísmo a princípio porque desejo argumentar que este é o fundamento de qualquer teoria que busque apreender as características intrínsecas - e não apenas contingentes - da urbanização. A proximidade e seu reflexo na acessibilidade é uma condição essencial para o efetivo surgimento de formas complexas de troca e interdependência que constituem a força vital da cidade. A busca por proximidade, por sua vez, promove a aglutinação de diversas atividades econômicas e sociais em pontos seletos de intensidade gravitacional elevada, com as maiores densidades ocorrendo invariavelmente no e em torno do centro da cidade. Os efeitos que emergem da competição espacial e do funcionamento do mercado de terras resultam, de tal maneira, em uma distribuição locacional de funções de tal forma que as diferentes partes da cidade passam a ser caracterizadas por formas especializadas de atividades e de usos do solo. A totalidade complexa e mutante constitui o que eu denominei em trabalhos anteriores de trama do solo urbano [urban land nexus] (SCOTT, 1980), embora, da forma como expus aqui, o conceito permanece, em alguma medida, um esqueleto formal carente de um conteúdo substantivo. Assim, nos deteremos agora no significado do conceito a partir de três indagações principais. Primeiro, o que é que, em geral, impulsiona a busca por proximidade? Segundo, e uma consequência 
disso, o que constitui especificamente a função (ou funções) central da cidade como tal? Terceiro, que tarefas administrativas e políticas são evocadas à medida que a lógica do espaço intraurbano se desdobra? As respostas a essas questões nos fornecem importantes pistas sobre a mola mestra da metrópole ressurgente.

Podemos pensar em diversas razões pelas quais um grande número de pessoas poderia querer participar de sistemas de atividade espacialmente aglomerados. Um fator comumente citado, por exemplo, é a busca por algum tipo de comunidade humana e cultural. Outro fator são as eficiências que podem ser obtidas com a construção de muitos tipos diferentes de infraestruturas físicas e sociais em um ambiente local compacto (GLAESER; GOTTLIEB, 2006). Porém, como um argumentum ad hominem inicial, parece difícil imaginar que o crescimento urbano massivo que ocorreu nas sociedades economicamente mais avançadas ao longo do último século possa ser atribuído simplesmente a algum tipo de impulso comunal ou aos altos custos dos artefatos infraestruturais. Esses fatores sem dúvida contribuem para o processo geral de urbanização, mas seus poderes de atração centrípeta devem, certamente, se exaurir muito antes da formação de grandes regiões metropolitanas como as que marcam a sociedade moderna. Parece muito menos provável que a emergência das principais cidades-regiões globais - como Nova York, Los Angeles, Londres, Paris, Tóquio, Cidade do México, Xangai etc. - possa ser explicada de tal forma. Para começar, qualquer processo de crescimento urbano só pode ser sustentado por uma expansão equivalente das oportunidades de emprego para a massa da população. Essas oportunidades são encontradas nas extensas redes de capital produtivo (industrial, serviços, comércio etc.) que expressam as interdependências que vinculam as unidades individuais de atividade econômica localizadas na cidade em um sistema eficaz. Além disso, essas redes não são apenas fontes inertes de emprego para a população; mais importante do que isso, elas são mecanismos sociais dinâmicos propensos a surtos expansionistas e, ocasionalmente, a penosas contrações. De qualquer modo, as grandes cidades são enormes nós de produção e trabalho que funcionam prioritariamente com base em suas firmas inter-relacionadas e seus densos mercados de trabalho local. Como veremos, o inerente dinamismo econômico desses sistemas alicerça-se nas propensões para o aprendizado e a inovação que tão frequentemente caracteriza as densas tramas de interação humana. Esses fenômenos constituem o motor principal do crescimento e desenvolvimento urbanos. O funcionamento desse motor gera intensas economias de aglomeração que estabelecem um vigoroso 
campo gravitacional. Assim, à medida que a produção e o trabalho são mobilizados, a cidade se expande pela contínua atração e agregação de novos elementos ao seu estoque de capital e trabalho. As cidades estão crescentemente enredadas em processos de globalização mas isso não significa necessariamente, como sugerem Amin e Thrift (2002), que elas deixem de funcionar como lugares de interdependência e poder econômico locais. Ao contrário, quanto mais a economia urbana se mostra capaz de conquistar mercados distantes, mais ela se torna capaz de crescer e se diferenciar internamente, reforçando, por sua vez, seu magnetismo aglomerativo. Sem dúvida, tendências contrárias de descentralização estão sempre em operação mas os processos de expansão urbana tenderam, até agora (com apenas interrupções ocasionais e temporárias), a sobrepujar qualquer tendência de declínio no longo prazo.

Precisamente porque a cidade não é apenas um agregado inerte de atividades econômicas, mas também um campo de efeitos emergentes na forma de economias de aglomeração e vantagens competitivas (assim como diversas formas de externalidades negativas), ela é, pela mesma razão, uma coletividade, no sentido de que o todo é muito maior que a soma das partes. Além disso, seu destino é em grande parte definido pelos efeitos coletivos que são uma das características essenciais da urbanização como tal. Esses efeitos constituem uma sorte de propriedade comum que não pode ser apropriada individualmente, mas cujos benefícios e custos são absorvidos de forma diferencial pelas diversas partes muitas vezes inconscientemente. Como tal essa propriedade comum resiste à lógica de mercado e, na falta de alguma ação racionalizada de ordem coletiva, é suscetível a sérios problemas no que se refere às formas pelas quais os benefícios e custos são produzidos e distribuídos pelo espaço urbano. Isso significa, por sua vez, que há um papel social intrinsecamente positivo às ações de mediação política e planejamento na cidade com o objetivo de buscar soluções para os problemas colocados pela propriedade comum em toda a sua complexidade. Em outras palavras, qualquer teoria viável do urbano deve não apenas atentar para as ações e comportamentos individuais, mas também para as formas específicas de ação coletiva dedicadas à solução dos problemas urbanos. Tais ações podem se originar em níveis extraurbanos de organização institucional, embora o princípio da complementaridade sugira que essas ações geralmente devam surgir como um elemento da própria sociedade local. Seu papel envolve na prática um esforço multifacetado dirigido tanto para o espaço da produção quanto para o espaço social da cidade, no sentido de aprimorar a oferta de externalidades positivas, de controlar externalidades negativas e outras 
rupturas urbanas e (em uma trajetória path-dependent de evolução urbana) assegurar que oportunidades benéficas que seriam desperdiçadas sejam aproveitadas tanto quanto possível.

É neste contexto abrangente que precisamos situar qualquer argumento acerca da ressurgência da metrópole moderna. Os comentários tecidos acima sugerem que é importante abordar este problema com um foco em questões de produção e trabalho combinados com uma percepção clara da lógica social do espaço intraurbano e da natureza intrinsecamente coletiva de sua dinâmica global. Algumas das mudanças mais importantes que estão ocorrendo atualmente nos padrões de urbanização ao redor do mundo têm suas raízes precisamente em grandes mudanças nas estruturas de atividade econômica, assim como na circunstância especial de que as cidades modernas estão crescentemente implicadas nos processos de globalização. A fim de preparar o terreno e consolidar algumas dessas ideias, começaremos com uma breve descrição de um modelo de urbanização anterior e em ampla medida deixado para trás. Essa história e sua relação com a urbanização pode parecer à primeira vista uma digressão, mas sua relevância tornar-se-á mais evidente na medida em que ela ilumina a problemática da urbanização esquematizada anteriormente, assim como lança luz sobre a crise urbana que precedeu o atual período de ressurgência urbana.

\section{Do crescimento à crise na sociedade de produção em massa fordista}

Durante a maior parte do século XX o modelo dominante (ainda que de modo algum exclusivo) de crescimento e desenvolvimento econômico na América do Norte e Europa Ocidental girou em torno dos mecanismos de produção em massa (CORIAT, 1979; PIORE; SABEL, 1984). Esse sistema de atividade econômica baseava-se em firmas líderes intensivas em capital, vinculadas a níveis inferiores formados por fornecedores diretos e indiretos, dando origem, assim, a polos de crescimento em setores industriais como o automobilístico, maquinário, de aparelhos domésticos, equipamento elétrico etc. (PERROUX, 1961). Os produtores envolvidos nesses polos de crescimento tendiam a se aglutinar no espaço geográfico, e muitos dos aglomerados industriais que daí resultaram constituíram o suporte fundamental para a formação de grandes e dinâmicas áreas metropolitanas. O sistema produtivo era constituído por uma divisão do trabalho dicotômica compreendida, de um lado, por trabalhadores fabris e, de outro, por profissionais de colarinho branco. Essa divisão do trabalho 
estampava-se, por assim dizer, no espaço urbano; ganhando expressão imperfeitamente, mas inequivocamente - em uma segmentação de bairros residenciais, sobre a qual ainda se sobrepunham padrões de segmentação social baseados nas diferenças de raça e origem nacional.

As regiões nodais da economia de produção em massa nos Estados Unidos e na Europa expandiram-se rapidamente na metade do século XX, à medida que novos investimentos eram aplicados em atividades produtivas e que fluxos de migrantes convergiam para os principais centros urbanos. Em que pese a incessante descentralização de filiais especializadas em atividades mais rotineiras para áreas periféricas de baixos salários, as regiões nodais continuaram a funcionar como polos fundamentais de crescimento econômico nacional, visto que as sinergias geradas no interior das grandes cidades do sistema de produção em massa mantinham-nas reiteradamente em posição de liderança econômica, como sugeriram Myrdal (1959) e Hirschman (1958). Além disso, a partir do New Deal a sociedade de produção em massa estava sob a influência crescente de políticas públicas formuladas com o objetivo de manter a prosperidade geral e o bem-estar social. Após a II Guerra Mundial, estas medidas se consolidaram em um sistema keynesiano de políticas públicas de bem-estar social, orientado para limitar os excessos cíclicos da economia da produção em massa e estabelecer uma rede de proteção social que contribuísse para manter as capacidades físicas e sociais da força de trabalho, especialmente em períodos de desemprego prolongado. Esse sistema de políticas públicas era gerido pelos governos centrais mas, como salientou Brenner (2004), era em grande medida dirigido especialmente para problemas urbanos (e implementado por órgãos municipais), e por isso teve impactos decisivos sobre o espaço urbano. Ao longo dos anos 1950 e 1960 as políticas de renovação urbana, os programas de moradia, a construção de um sistema intraurbano de vias expressas, a expansão suburbana e os variados programas de bem-estar social desempenharam as funções de manter o crescimento econômico e assegurar que os nós urbanos desse crescimento continuassem a operar de forma eficiente e socialmente administrável.

Por volta do início dos anos 1970, o sistema de produção em massa na América do Norte e na Europa Ocidental começava a dar sinais de dificuldade; e à medida que a década transcorria esse sistema entrava em uma fase de exaustão e reestruturação. Não nos deteremos aqui sobre os pormenores dessas mudanças, exceto para observar que o padrão endêmico de descentralização da produção para longe das regiões nodais havia se transformado, no início dos anos 1970, em uma torrente; e as cidades industriais até então prósperas defrontavam-se com vultosas perdas de 
emprego e declínio econômico. A desindustrialização das regiões manufatureiras antigas avançou em um ritmo acelerado durante os anos 1970 e, com o aprofundamento da crise, o cinturão manufatureiro dos Estados Unidos ficou mais comumente conhecido como Rustbelt. Nas áreas metropolitanas que haviam funcionado como os centros privilegiados da expansão do pós-guerra as palavras do dia eram agora estagnação e declínio, especialmente nas áreas centrais dessas cidades onde resíduos de núcleos residenciais da classe trabalhadora estavam marcados por uma síndrome profunda de desemprego, pobreza e abandono. Nos EUA, mesmo aquelas regiões metropolitanas que haviam enfrentado a crise econômica relativamente bem tiveram suas áreas centrais profundamente afetadas pela descentralização industrial e a reestruturação. A essa altura, além disso, boa parte dos empregos perdidos não mais se direcionava unicamente para as periferias nacionais, mas dirigia-se crescentemente para áreas de baixos salários na periferia global.

Pesquisadores como Carney et al (1980), Bluestone e Harrison (1982) e Massey e Meegan (1982) publicavam, então, análises sombrias sobre as possibilidades econômicas das cidades e regiões que mais haviam se beneficiado do crescimento ocorrido na expansão do pós-guerra. Para muitos desses teóricos, a perspectiva de uma recuperação urbana vigorosa parecia muito improvável. A agenda política neoliberal iniciada por Reagan nos EUA e Thatcher na Grã-Bretanha consolidou esse pessimismo em muitos lugares, uma vez que os principais pilares de sustentação do sistema keynesiano de bem-estar eram paulatinamente desmantelados (embora o mesmo não se possa dizer do gasto público) e mais e mais empregos industriais estáveis e bem pagos desapareciam permanentemente da cena urbana.

\section{Entrando no século XXI}

\section{Cidades e a nova divisão do trabalho}

No início dos anos 1980, no momento em que este pessimismo parecia atingir seu ápice, os sinais de um modelo alternativo de organização e desenvolvimento econômico começaram a aparecer em vários lugares. Muitas tentativas incipientes de conceituar esse modelo foram formuladas sob a designação de "indústrias emergentes" [sunrise industries], "especialização flexível", "pós-fordismo" ou simplesmente a "nova economia" (cf. BAGNASCO, 1977; PIORE; SABEL, 1984; MARKUSEN et al, 1986; ESSER; HIRSCH, 1989). Ademais, e desde o 
começo desses esforços de elaboração conceitual, muitos estudiosos perceberam que um novo surto de aglomeração e urbanização parecia ser uma consequência do novo modelo afetando várias regiões que tinham permanecido à margem das principais ondas de industrialização no imediato pós-guerra, como o Sunbelt americano ou a Terceira Itália.

Discutia-se muito - e ainda discute-se - sobre o caráter e o significado da nova economia que começou a emergir há cerca de duas ou trềs décadas (ex. GERTLER, 1988; SAYER, 1989; HYMAN, 1991; POLLERT, 1991) $)^{3}$. Sejam quais forem as controvérsias que estiverem em causa a esse respeito, não parece haver muitas discordâncias atualmente sobre o fato de que um grupo de setores muito peculiar, caracterizado por processos produtivos pouco padronizados e práticas de trabalho relativamente flexíveis, começou a se deslocar gradativamente para a linha de frente do desenvolvimento econômico naquele momento, e continuou a se expandir rapidamente até o presente. Este grupo de setores inclui a indústria intensiva em tecnologia, os serviços (empresariais, financeiros e pessoais), indústrias de produção cultural (como a mídia, o cinema, a música e o turismo) e formas de produção baseadas no design neoartesanal e voltadas para a moda, como vestuário, mobiliário e joalheria. Esses e outros setores afins suplantaram em grande medida as indústrias de produção em massa como os motores principais do crescimento e inovação nos mais importantes centros do capitalismo mundial, onde eles constituem os alicerces do que podemos denominar como uma nova economia cultural-cognitiva (ver também RULLANI, 2000; MOULIER BOUTANG, 2007; VERCELLONE, 2007). A base de sustentação dessa nova economia é constituída de um estrato de profissionais liberais e profissionais técnicos de gestão e de criação dedicados a tarefas que podem ser concebidas, em termos genéricos, como de pesquisa científica e tecnológica, atividades administrativas e de negócios, representação e transação, gerenciamento e supervisão de projetos, concepção e design, criação de imagem e entretenimento etc. Essa base é, ao mesmo tempo, complementada e organicamente inter-relacionada com um segundo estrato composto por trabalhadores mal remunerados e, via de regra, subalternos, empregados tanto em trabalhos manuais (por exemplo na produção têxtil ou na montagem de componentes de alta tecnologia), como em serviços precários (limpeza de escritório, hotelaria e restaurantes, serviços gerais, prestação

\footnotetext{
${ }^{3}$ Estritamente falando, as raízes da nova economia podem ser localizadas nos anos $1960 \mathrm{e}$ até mesmo nos anos 1950 se considerarmos precursores como Hollywood depois do decreto Paramount de 1948 ou o Vale do Silício depois da metade da década de 1950.
} 
de cuidados a crianças, etc.). Embora as tarefas realizadas por esses trabalhadores do estrato mais baixo sejam frequentemente repetitivas, há, mesmo nesse caso, uma certa tendência - especialmente nas grandes cidades americanas - de muitas dessas funções exigirem algum grau de flexibilidade e discernimento cognitivo e/ou sensibilidade cultural da parte dos empregados (McDOWELL et al., 2007).

Scott et al (2003) e Levy e Murnane (2004) sugeriram, apropriadamente, que o crescimento absoluto e relativo dos processos de trabalho pouco padronizados na economia americana nas últimas décadas pode ser mais bem compreendido como uma consequência da paulatina incursão das tecnologias de computação no local de trabalho. Eles apontam que, à medida que a computação avançou, muitos tipos diferentes de empregos padronizados foram eliminados tanto na parte administrativa quanto na produção direta. Empregos como contabilidade, arquivamento, ocupações de escritório de baixa qualificação e trabalhos manuais repetitivos estão sendo rapidamente substituídos por tecnologias digitais, liberando, assim, força de trabalho para formas de trabalho menos padronizadas. Evidentemente, outros dois fatores importantes precisam ser considerados aqui. Um é expresso pela Lei de Engel, que indica que à medida que os níveis de rendimento se elevam, as famílias tendem a gastar proporcionalmente mais em satisfações não-essenciais (muitas das quais são produzidas pelos setores cultural-cognitivos). $\mathrm{O}$ outro fator refere-se ao contínuo deslocamento do trabalho fabril para o exterior e essa tendência, sem dúvida, explica, ao menos em parte, o declínio dos empregos manuais rotineiros nas grandes cidades americanas. Seja qual for a dinâmica exata dessa reestruturação econômica abrangente, o crescimento da economia cultural-cognitiva parece agora estar avançando a um ritmo acelerado. A mesma tendência foi complementada por uma disparidade crescente nos níveis de rendimento médio individual entre os dois principais estratos da nova economia (SCOTT et al, 2006).

A economia cultural-cognitiva, portanto, é caracterizada por uma nova divisão do trabalho baseada em sistemas de produção crescentemente flexíveis e maleáveis (com um leque cada vez mais variado de bens e serviços) que estão hoje na ponta de lança da economia contemporânea. Com efeito, a economia cultural-cognitiva está, além disso, altamente concentrada nas áreas urbanas e muitos dos seus segmentos mais dinâmicos possuem uma afinidade peculiar com as principais cidadesregiões globais como Nova York, Los Angeles, Londres, Paris ou Tóquio (SASSEN, 1994; DANIELS, 1995; PRATT, 1997; KRÄTKE; TAYLOR, 2004; TAYLOR, 2005). Com frequência, nessa nova economia, 
aglomerados singulares de firmas conformam distritos industriais especializados no interior do tecido urbano. Esses aglomerados coexistem com uma gama de prestadores de serviços auxiliares e firmas subcontratadas. $\mathrm{Na}$ realidade, pode-se verificar frequentemente uma geografia intraurbana característica da nova economia, em que os setores de serviços e de atividades baseadas em design (por exemplo serviços financeiros e empresariais, mídia, indústria da moda etc.) localizam-se em distritos especializados nas proximidades do centro da cidade, enquanto que os setores mais intensivos em tecnologia (por exemplo eletrônica, biotecnologia, aeroespacial etc.) tendem a se instalar em aglomerações ou tecnopolos localizados em áreas mais afastadas (SCOTT, 2002). Evidentemente essa geografia intraurbana representa, na melhor das hipóteses, uma tendência geral e nunca se concretiza senão de forma aproximada.

A atração que a cidade exerce sobre as indústrias culturalcognitivas se explica prioritariamente pela lógica organizacional da nova economia, ao que se acrescenta a forma pela qual os riscos e incertezas que caracterizam essas indústrias são mitigados pelo tamanho e a densidade do meio urbano. Diferentemente da produção em massa de tipo fordista, a economia cultural-cognitiva baseia-se em pequenos ciclos de produção, marketing de nicho e competição monopolística (no sentido de Chamberlin), e seus setores principais tendem a ser marcados radicalmente por baixos níveis de padronização e rotinização. Os produtores individuais estão quase invariavelmente articulados em densas redes de transação mercantil com outros produtores, frequentemente em situações nas quais o contato interpessoal é necessário para a intermediação bem-sucedida dos negócios de interesse comum. Essas redes, ademais, são propensas à grande instabilidade, na medida em que as firmas modificam suas configurações de processo e produto, oscilando constantemente de um conjunto de insumos a outro. Da mesma forma, os mercados de trabalho locais estão submetidos à grande imprevisibilidade como consequência da volatilidade dos mercados e do crescimento de formas de emprego temporário, de tempo parcial e por conta própria [freelance], mesmo entre trabalhadores bem remunerados e altamente qualificados (ANGEL, 1991; BLAIR, 2001). Essa situação é acentuada pela expansão recente das ocupações vinculadas a projetos, nas quais grupos de trabalhadores são reunidos para executar projetos multidimensionais que requerem uma variedade de capacidades e talentos dentro de um determinado horizonte de tempo (GRABHER, 2004). Uma vez que o projeto é concluído, o grupo é 
dissolvido e pelo menos alguns dos seus membros veem-se obrigados a procurar novas ocupações.

Essas características da economia cultural-cognitiva incentivam um grau significativo de convergência locacional dos produtores individuais e trabalhadores para determinadas áreas urbanas, não apenas como uma maneira de reduzir os custos espaciais de interação mútua, mas também como um instrumento que lhes permite explorar os efeitos de retornos crescentes que emergem da redução de riscos proporcionada pela reunião de oportunidades latentes (SCOTT, 2005). Contudo, há ainda um fator adicional que contribui muito para esse processo de convergência; na medida que as firmas e trabalhadores em interação se aglutinam em um lugar, e que processos complementares de desenvolvimento urbano são colocados em marcha, um campo singular de energias inovadoras aflora no sentido de que os laços e nós do organismo como um todo começam a funcionar como um sistema de comunicações complexo e cambiante, caracterizado por abundantes contatos interpessoais e trocas informais de informação (STORPER; VENABLES, 2004). A maior parte das informações que circula de tal maneira é, sem dúvida, não mais do que ruído aleatório. Uma parte dessas informações, porém, é ocasionalmente de utilidade direta e parcelas diferentes desse conjunto de informações tácitas ou explícitas - algumas vezes se combinam de forma a originar novas ideias e sensibilidades sobre os processos de produção - o design de produtos, os mercados etc. Dessa maneira, os efeitos de um vigoroso campo criativo são continuamente mobilizados por todo o espaço intraurbano, resultando em processos de aprendizado e inovação que, embora individualmente possam ser pouco significativos, cumulativamente são expressivos.

Estas observações contribuem para esclarecer por que a nova economia cultural-cognitiva possui tamanha afinidade com as áreas urbanas. A decisiva expansão da economia cultural-cognitiva e de setores afins, por sua vez, explica em grande parte a ressurgência urbana que ocorreu de forma tão dramática nas últimas décadas. Até mesmo centros industriais antigos e até há pouco em declínio (como várias cidades grandes no Manufacturing Belt americano, algumas partes do norte da Inglaterra e a região do Ruhr na Alemanha) experimentam hoje um renascimento, na medida que começam a integrar a nova ordem econômica (O’CONNOR, 1998; STADTart, 2000). Dito isto, convém reiterar que a ressurgência está também associada a uma inequívoca e crescente polarização dos rendimentos e das oportunidades nas cidades onde esses 
processos ganharam maior evidência, um fato exacerbado pela demanda voraz da nova economia por trabalhadores imigrantes mal remunerados.

\section{Urbs et orbis}

A ressurgência contemporânea das cidades inscreve-se e é amplificada por uma tendência ao aprofundamento da globalização. Essa tendência ganha expressão na imensa extensão geográfica dos mercados que cada cidade é capaz de suprir. A globalização, ademais, viabilizou fluxos internacionais cada vez maiores de trabalhadores (qualificados e não-qualificados) para as regiões metropolitanas mais dinâmicas do mundo.

As cidades mais atingidas por esses processos experimentaram não apenas profundas mudanças nas suas estruturas econômicas e demográficas mas também, com frequência, em sua constituição física. Em primeiro lugar, essas mudanças foram provocadas pela gentrificação que vem ocorrendo ao longo das últimas décadas em bairros antigos de ocupação trabalhadora, especialmente aqueles situados nas proximidades das áreas mais centrais das cidades. Esses bairros são notoriamente suscetíveis à colonização pela nova elite cultural-cognitiva em decorrência da demanda desse grupo social por um local de moradia com fácil acesso às áreas centrais, onde se localizam a maior parte dos seus empregos. Em segundo lugar, as mudanças físicas nas cidades podem ser atribuídas também aos projetos de investimento de grandes organizações corporativas e às intervenções de renovação urbana dos governos municipais visando melhorar o prestígio de suas cidades enquanto centros econômicos e culturais de alcance global (SMITH, 2002). Estas atividades com frequência ganham corpo em novos equipamentos culturais, recreativos e de consumo na cidade; ocasionalmente promovem a renovação de antigos edifícios industriais e comerciais, que são convertidos em salas de concerto, galerias de arte, teatros, shopping centers, etc. Possivelmente o exemplo mais notável desse impulso de transformação pode ser encontrado na atual tendência de erigir estruturas arquitetônicas de proporções monumentais em grandes regiões metropolitanas com ambições globais. Alguns dos exemplos mais marcantes dessa moda podem ser observados em um grupo de grandes cidades-regiões asiáticas como Hong Kong (HONG KONG CENTRAL POLICY UNIT, 2003), Kuala Lumpur (BUNNELL et al, 2002), Xangai (HUANG, 2006) e Cingapura (YEOH, 2005), onde se tem empreendido um esforço sistemático não apenas no 
sentido de ingressar decisivamente na era da produção cultural-cognitiva mas também de divulgar, por meio de marcas visíveis, a condição dessas cidades enquanto postos de comando da nova ordem global; e também como centros de atração para grandes investidores e para uma força de trabalho cosmopolita e altamente qualificada. Essas diferentes facetas da metrópole ressurgente se combinam em sinergias de sustentação mútua em que a economia urbana, a força de trabalho cultural-cognitiva e o ambiente físico contribuem, todos eles, para uma dinâmica de desenvolvimento que requer uma incessante melhoria da atratividade e significância simbólica da cidade, juntamente com um domínio crescente ou potencial da parte dos produtores locais sobre nichos de mercado de alcance global.

$\mathrm{Na}$ medida em que se desenvolvem essas tendências, os padrões geográficos e a própria lógica da globalização são modelados e remodelados de inúmeras maneiras. No antigo modelo de desenvolvimento baseado no binômio centro-periferia as áreas metropolitanas dos países capitalistas avançados eram vistas, essencialmente, como parasitárias em relação ao trabalho de baixo custo da periferia em decorrência do desenvolvimento e do intercâmbio desiguais (EMMANUEL, 1969; AMIN, 1973). Um esforço de renovar esse modelo foi empreendido por Fröbel et al. (1980) em sua teoria da Nova Divisão Internacional do Trabalho, na qual os autores argumentam que os países centrais tendem a se desenvolver como centros especializados em trabalhos intelectuais (comando, controle, pesquisa e desenvolvimento etc.), enquanto que a periferia torna-se um amplo repositório de trabalho fabril padronizado. Quaisquer que sejam os méritos ou deméritos desses argumentos no momento em que foram elaborados, nenhum deles se sustenta diante das especificidades que assumem os processos de urbanização e globalização na atualidade. Em particular, a ascensão da economia cultural-cognitiva, com seu subterrâneo composto de sweatshops e atividades de serviços subalternos que empregam inúmeros trabalhadores imigrantes pouco qualificados, tem como resultado o fato de que as principais cidades dos países centrais estão agora entremeadas de um número crescente de enclaves do "terceiro mundo", ao passo que muitas partes do que havia sido a periferia tornaramse núcleos avançados de produção qualificada e intensiva em tecnologia, serviços financeiros e corporativos e indústrias culturais. Sem dúvida, ainda pode-se identificar importantes componentes do modelo centroperiferia na grande expansão da subcontratação internacional de atividades oriundas dos países de mão-de-obra cara para os países de mão-de-obra barata, um fenômeno que cresceu nas últimas décadas (GEREFFI, 1995; SCHMITZ, 2007). Apesar desses ecos contínuos, a antiga divisão centro- 
periferia que caracterizava o desenvolvimento econômico internacional parece estar sendo gradativamente superada por uma estrutura geográfica alternativa composta por um mosaico global de cidades ressurgentes que operam cada vez mais como motores econômicos e agentes políticos no cenário global. Nem todas essas cidades participam igualmente da economia cultural-cognitiva, ainda que todas elas estejam interconectadas por relações de competição e colaboração de abrangência global. Aquelas que emergiram ou estão emergindo como líderes na economia culturalcognitiva funcionam, cada vez mais, como centros principais do sistema global contemporâneo.

Nesse contexto as cidades ressurgentes e cidades-regiões de hoje estão, evidentemente, começando a adquirir um grau de autonomia econômica e política que seria quase inimaginável na era fordista pretérita, quando o Estado e a economia nacional representavam as duas faces de uma estrutura soberana de ordem social e autoridade política. Em sintonia com o rearranjo das escalas espaciais da economia e da sociedade que vem ocorrendo com o curso da globalização, distingue-se cada vez mais uma espécie de novo regionalismo. Referimo-nos aqui a uma situação na qual as cidades e as cidades-regiões - à medida em que as identidades individuais, a vida social e as estruturas institucionais são submetidas a uma reconstituição em diversas escalas de resolução espacial - começam, então, a ganhar proeminência como componentes funcionais do sistema mundial. Diante dessas considerações as especulações incipientes de Jacobs (1969), sobre as cidades serem mais adequadas do que os Estados para operar como unidades orgânicas de organização econômica e da vida social, devem ser vistas como surpreendentemente prescientes. Com efeito, o declínio do Estado de bem-estar keynesiano e a descentralização do poder central em um contexto de insistente prioridade aos mercados e à competitividade ajudou a aproximar o conteúdo dessas especulações à realidade concreta. As principais cidades-regiões estão, em toda parte, lidando com uma gama de experimentos sociais na tentativa de consolidar suas vantagens competitivas diante dos constrangimentos crescentes impostos pela globalização, assim como elas e seus cidadãos de forma geral buscam arranjos institucionais locais aptos a responder efetivamente às necessidades e objetivos econômicos locais singulares. Em uma era de neoliberalismo e globalização ascendentes, quando os governos nacionais mostram-se cada vez menos capazes ou desejosos de atender aos diferentes interesses regionais e setoriais sob sua jurisdição, as cidades precisam tomar a iniciativa de construir as bases de sua competitividade, ou enfrentar as consequências negativas da inação. Uma expressão notável 
dessa tendência - especialmente nas grandes cidades-regiões globais refere-se à percepção cada vez mais aguda de que algum tipo de coordenação administrativa e institucional sobre a organização espacial da cidade como um todo é uma condição necessária para se obter eficiência, operacionalidade e vantagens competitivas locais. A força dessa consciência é tamanha que tem estimulado diversos experimentos por parte dos governos locais em diferentes lugares, incluindo a construção ou proposta de construção de estruturas de governança metropolitana transfronteiriças, como na região de Øresund na Escandinávia, no delta do rio das Pérolas no sul da China, ou - mais destacadamente, talvez - na região de San Diego e Tijuana na fronteira entre Estados Unidos e México.

\section{Vida e política na metrópole ressurgente}

A metrópole ressurgente contemporânea difere marcadamente, portanto, da cidade industrial fordista da metade do século XX. Isso é evidente no que se refere às bases econômicas desses dois tipos de cidade. Suas estruturas sociais oferecem também inúmeros contrastes. Assim, enquanto que a vida social na cidade fordista era, em grande medida, organizada em torno de padrão clássico de separação entre trabalhadores fabris e de colarinho branco, a atual metrópole ressurgente é mais comumente caracterizada por uma profunda cisão entre uma nova elite de trabalhadores cultural-cognitivos e uma massa de trabalhadores mal remunerados e de baixa qualificação, formando uma espécie de lumpemproletariado urbano, sendo uma grande proporção composta de imigrantes. A metrópole fordista, evidentemente, também era destino de migração, tanto doméstica quanto estrangeira (especialmente europeia); e ela certamente era marcada por significativa diversidade racial e de origem nacional. Entretanto a metrópole ressurgente atual é ainda mais diversa no que tange à sua composição étnica e cultural e, mais importante, é um ponto de atração de imigrantes qualificados e não-qualificados de regiões menos desenvolvidas do mundo, como a Ásia e a América Latina. O resultado disso é uma nova espécie de cosmopolitismo das populações dessas cidades (BINNIE et al., 2006). Não tanto o cosmopolitismo rarefeito do período anterior, cuja característica definidora referia-se a um grupo de indivíduos desenraizados de origens indeterminadas mas com pretensões de ascender à elite, mas, antes, um cosmopolitismo cotidiano que aceita uma mescla eclética de identidades e culturas urbanas como um aspecto perfeitamente normal da vida moderna. 
Há pouco mais de um século Simmel ([1903] 1959) caracterizou os habitantes da cidade moderna como uma massa de indivíduos mecanicamente interconectados mas psicologicamente desconectados. Sem dúvida essa caracterização continua em grande medida válida no contexto da metrópole ressurgente, com seus ritmos sincronizados de trabalho e formas atomizadas de vida social. O individualismo da sociedade urbana avançou bastante em comparação com as cidades da média e alta modernidade. Muitas evidências indicam que as tradicionais tramas comunitárias e de solidariedade baseadas na cidade ou na vizinhança continuam se desintegrando, enquanto que as normas da ordem mercantil e os critérios utilitários de avaliação humana penetram ainda mais profundamente no tecido da existência social. Sennett (1998), por exemplo, apontou para uma aparente corrosão das formas tradicionais de afetividade e confiança tanto no local de trabalho quanto na vida social, ao passo que Putnam (2000) fez considerações mais gerais sobre o enfraquecimento dos laços comunitários nos Estados Unidos. Mesmo a tendência que aparentemente marcha no sentido oposto, de expansão da sociedade civil ONGs, organizações não-lucrativas, fundações filantrópicas etc. -, parece ser mais um sinal de processos subjacentes de fragmentação social e recuo dos governos formais do que um sinal de solidariedade política e mobilização em torno de normas comunitárias (MAYER, 2003). Ainda assim, as novas formas de consumismo e rituais sociais hedonísticos da vida urbana contemporânea oferecem alguma espécie de compensação diante do que Simmel denominou a dureza inexorável das cidades, ao menos para os segmentos privilegiados da sociedade. Lloyd e Clark (2001) aludem a algo que estamos buscando aqui em sua descrição da moderna metrópole como uma 'máquina de entretenimento'; ou seja, como um lugar no qual espaços privilegiados são destinados ao espetáculo urbano, a experiências de consumo de luxo, formas de entretenimento e vida noturna, suplementadas por doses ocasionais de aprimoramento cultural proporcionado por museus, galerias de arte, salas de concerto, etc. Esses espaços combinam-se harmoniosamente, tanto em termos formais quanto funcionais, com os bairros residenciais gentrificados e locais de trabalho diferenciados que são um território privilegiado das camadas superiores da força de trabalho urbana na moderna economia cultural-cognitiva.

Eu já havia assinalado que a vida e o trabalho na cidade ressurgente submetem-se a níveis elevados de risco tanto para os trabalhadores das camadas superiores quanto aos das camadas inferiores. Na medida em que são gradativamente reduzidas as políticas de bem-estar social e que as organizações sindicais tradicionais se enfraquecem na sociedade 
contemporânea, os trabalhadores menos qualificados em particular são expostos às pressões exercidas por essa situação, em especial aqueles que compõem o grande e crescente contingente de trabalhadores imigrantes marginalizados (e muitas vezes ilegais). Os profissionais mais qualificados, por sua vez, geralmente dispõem de recursos - humanos e financeiros - que proporcionam alguma segurança em relação aos efeitos mais deletérios do risco e, em certos casos, eles são, além disso, protegidos pelas organizações profissionais e associações que contribuem para assegurar um mínimo de estabilidade no mercado de trabalho. Ainda assim, mesmo para essa camada de profissionais a imprevisibilidade crescente das perspectivas de emprego impõe problemas sérios, especialmente para indivíduos no início de suas carreiras profissionais. Muitos desses indivíduos não estão mais engajados em carreiras que envolvem uma mobilidade quase natural dentro da empresa e muitas das firmas que os empregam não possuem mais internamente o tradicional departamento de gestão de pessoas. Pelo contrário, os trabalhadores mais qualificados cada vez mais gerenciam suas próprias carreiras conforme mudam de projeto e de emprego, consolidando gradualmente uma reputação e acumulando uma sucessão de experiências. Essa forma de operar é intimamente dependente da formação de redes sociais formais e informais que possibilitam ao trabalhador individual trocar informações, manter-se a par dos últimos acontecimentos em suas áreas de atuação e formar uma rede de conhecidos que podem ser acionados para indicações e auxílio quando necessário. Os profissionais de alta qualificação são participantes constantes nessas redes multifacetadas, que se proliferam em torno de objetivos relacionados ao exercício da profíssão em cidades onde a nova economia cultural-cognitiva está altamente desenvolvida (SCOTT, 1998; URSELL, 2000; BATT et al., 2000; BLAIR, 2001; NEFF et al., 2005).

Esse é um mundo, porém, no qual as possibilidades de ampla mobilização política parecem cada vez mais remotas; e a ação coletiva por parte das autoridades municipais parece assumir cada vez mais a forma de uma atividade profissionalizada e tecnocrática que está distanciada da esfera da contestação política mais direta. Pela mesma razão o conflito intraurbano em torno dos impactos sociais e distributivos do planejamento, que era tão característico no passado (e que reverberou especialmente sobre os bairros de trabalhadores na cidade fordista), ficou, em grande parte, relegado ao segundo plano. Em alguma medida, os únicos resquícios que permanecem da atmosfera política combativa da grande metrópole (cada vez menos) emanam das reivindicações e conflitos identitários que parecem agora ter sobrepujado as lutas políticas populares por justiça 
econômica. No entanto, mesmo na sua forma atual relativamente despolitizada, a ação coletiva na metrópole ressurgente é muito mais do que meramente uma força neutra ou desinteressada. As autoridades locais atuais privilegiam incisivamente as necessidades dos negócios (HARVEY, 1989) e quase em toda parte estão comprometidas com políticas destinadas a sustentar as vantagens competitivas locais e atrair investidores externos. Grandes projetos de requalificação, investimentos em amenidades urbanas, marketing urbano, a promoção de festivais locais e grandes eventos esportivos etc. figuram com proeminência entre esses tipos de iniciativas e tornaram-se, efetivamente, um terreno de competição interurbana na era global.

Um desdobramento concomitante da cena política urbana tem sido a preocupação crescente com questões relativas à "criatividade" e uma procura mais enérgica por instrumentos que possam direcionar as forças da criatividade com o objetivo de promover o desenvolvimento econômico local (FLORIDA, 2004). Abordei em outro trabalho, em alguma medida, a noção profundamente problemática de cidade criativa (SCOTT, 2006). Não é meu objetivo examinar detidamente essa questão específica, exceto para registrar en passent que a ascensão de uma economia cultural-cognitiva nas principais cidades mundiais insere decisivamente - como era de se prever as aspirações à criatividade no centro da agenda política urbana. Cidades como Nova York, Londres, Paris, Sydney, Tóquio, Osaka, Hong Kong, Seul e Cingapura, entre outras, empenham-se explicitamente em promover sua condição de cidades criativas e centros globais da nova economia cultural-cognitiva (ver, por exemplo, CHANG, 2000; British Department of Culture, 2001; Hong Kong Central Policy Unit, 2003; IAURIF, 2006; STADTart, 2000) e há muitas razões para crer que elas continuarão a intensificar a busca por esse gênero de influência econômica e cultural no futuro.

Com efeito, a discussão normativa sobre as cidades criativas na literatura atual enfatiza, em grande medida, a suposta eficácia da receptividade, tolerância e diversidade social como a base para avançar nesse aspecto. Essas qualidades são, sem dúvida, excelentes por si mesmas e não se pode questionar que a maioria das pessoas preferiria viver em cidades em que esses atributos vicejam, ao invés daquelas marcadas pela insensibilidade, intolerância e homogeneidade. A importância dessas qualidades como elementos ativos nos processos de desenvolvimento econômico permanece contudo duvidosa e, além disso, não está sequer claro qual é sua relevância específica para a constituição da cidade enquanto uma comunidade cultural. De fato a fórmula da receptividade, 
tolerância e diversidade - sem especificações adicionais - pode servir tanto como uma base para o isolamento, o individualismo e a mera diferença mecânica, quanto pode servir para a solidariedade, o companheirismo e o envolvimento político profundo dos cidadãos na vida urbana. Algo do gênero já pode ser observado nas cidades ressurgentes dos Estados Unidos atual, onde os elementos dessa fórmula estão certamente mais presentes hoje do que jamais estiveram; mas o bem-estar econômico e social da comunidade urbana como um todo permanece em baixa e muitas das tensões estruturais básicas da vida urbana não chegam a se elevar, de forma durável, ao nível da consciência pública. Evidentemente esta é, em parte, a causa pela qual essas mesmas tensões ocasionalmente eclodem na forma de conflitos espontâneos. Pode-se exemplificar isto com as revoltas de Los Angeles em 1992, assim como com os distúrbios que eclodiram nos subúrbios de imigrantes em Paris, no final de 2005, e que se alastraram depois a outras partes da região metropolitana. $\mathrm{O}$ paradoxo da metrópole ressurgente é o contraste que se exacerba entre sua superfície reluzente e a precariedade subterrânea - apesar das exaltações, cada vez mais comuns, às virtudes da receptividade, tolerância e diversidade da sociedade americana.

\section{Conclusão: perspectivas e desafios}

A reflexão aqui desenvolvida acerca das condições da cidade levounos a abordar desde questões relativas à organização do espaço intraurbano, passando pela investigação do crescimento de uma economia cultural-cognitiva simultaneamente global e local; para, finalmente, retornarmos ao espaço interno da cidade como um lugar singular de tensões e possibilidades políticas. Desde a crise geral do fordismo nos anos 1970 e início dos anos 1980 as cidades retomaram sua espiral de expansão de longo prazo; e com a ascensão da economia cultural-cognitiva algumas cidades do mundo demonstraram uma extraordinária capacidade de crescimento, inovação e renovação demográfica. Em que pese os argumentos atuais que defendem que a globalização e a internet estão prestes a transformar a sociedade humana em um espaço de fluxos em que o lugar haveria perdido importância, o avanço inexorável da urbanização segue seu curso. Como demonstramos, esse avanço tem sido acompanhado em muitos casos por mudanças qualitativas dramáticas na forma interna $\mathrm{e}$ nas funções da cidade, ainda que sempre num contexto de uma dinâmica urbana básica assentada em uma estrutura de localizações e usos do solo funcionalmente polarizados (ou multipolarizados). Ao mesmo tempo, as grandes cidades desempenham um papel muito importante como 
componentes fundamentais de um novo regionalismo - isto é, como sistemas localizados de interações diárias trabalho-vida social que constituem parte de uma rede de relações globais mais amplas. Neste sentido a globalização pode ser entendida em parte pelo mosaico de cidades e cidades-regiões interconectadas que formam sua base de apoio locacional.

À luz desta discussão, pode-se discernir nas cidades contemporâneas três desafios principais no que diz respeito à governança regional, ao crescimento econômico e à igualdade social. Sem dúvida esses desafios remontam aos primórdios da urbanização capitalista, embora sua forma varie significativamente de um período histórico ao outro. Esses desafios assumem maior premência na medida em que as cidades ressurgentes continuam a ganhar ímpeto. O primeiro desafio decorre das disfuncionalidades e ineficiências generalizadas que emergem quando o espaço intraurbano está política e administrativamente fragmentado, em especial nas cidades globais dispersas da atualidade. É de vital importância, nesses casos, reconhecer as múltiplas interdependências e extravasamentos que desrespeitam qualquer padrão de divisão municipal e adaptar as estruturas institucionais da governança urbana. Apesar desse imperativo sistêmico, as dificuldades de implementação prática são enormes e é sempre provável o aparecimento de focos de resistência profunda à integração política metropolitana, como ilustra a história recente de Montreal (BOUDREAU et al., 2006). O segundo desafio referese à construção e manutenção do dinamismo econômico e cultural urbano diante das crescentes ameaças e oportunidades da globalização. O êxito nesse quesito dependerá, em grande medida, do alcance atingido no equacionamento do primeiro desafio, mas este segundo desafio também coloca uma série de questões singulares e perturbadoras acerca de como exatamente os políticos deveriam proceder em sua tentativa de coordenar e intensificar as vantagens competitivas locais na era da economia culturalcognitiva. Em particular, precisamos sem dúvida abandonar concepções abstratas da criatividade e visões idealistas do poder do talento etéreo e reformular as questões básicas em termos de planos de desenvolvimento concretos centrados em dinâmicas setoriais específicas e na busca por oportunidades tangíveis de emprego. O terceiro e indubitavelmente mais complicado desafio refere-se às gritantes desigualdades de renda, oportunidades e chances de vida que afligem a metrópole contemporânea e que, provavelmente, abalam o desenvolvimento pleno das suas potencialidades culturais e econômicas. A esse desafio, soma-se o vazio que precisa ser preenchido relativo às possibilidades de participação 
democrática nas questões de ordem pública da cidade e a necessidade complementar de incorporar todos os segmentos de uma sociedade urbana cada vez mais cindida em uma forma ou outra de comunidade política, capaz de articular algum sentido de destino comum e inibir o narcisismo pernicioso que parece tanto impregnar a vida na grande metrópole atual.

Para além destes desafios bastante específicos que as cidades individuais devem enfrentar, uma questão maior pode ser trazida à tona acerca da comunidade global de cidades como um todo. Como vimos, as cidades estão cada vez mais submetidas a uma integração funcional global na forma de um sistema de comércio, interação e troca informacional de longa distância. É muito difícil dimensionar as consequências últimas desse processo de integração. Dito isto, pode-se afirmar, baseado em noções a respeito da interação entre economias de aglomeração e competição chamberliniana, que este processo resultará com o tempo em um sistema crescentemente policêntrico e polifônico de produção econômica e cultural (SCOTT, 2005), em contraste com a paisagem homogeneizada que alguns analistas afirmam ser um resultado provável da globalização. De todo modo, haverá sem dúvida pressões crescentes por uma coordenação sistêmica, como consequência desta situação, tanto para equacionar desequilíbrios persistentes entre cidades quando estes surgirem, quanto para mediar conflitos em torno dos custos e benefícios (econômicos e culturais) diferenciais da participação neste mosaico global. Assim, no longo prazo alguma forma institucional de absorção das tensões e resolução de conflitos em uma eventual união global de sistemas de cidades deverá ser desenvolvida, para além das estruturas atualmente existentes de consulta e cooperação internacional.

\section{METRÓPOLE RESSURGENTE: ECONOMIA, SOCIEDADE E URBANIZAÇÃO EM UM MUNDO INTERCONECTADO}

Resumo: Uma problemática urbana é identificada acerca das características essenciais das cidades enquanto conjuntos de atividade humana espacialmente polarizados e marcados por simbiose interna elevada. As raízes da crise da metrópole industrial clássica do século XX são identificadas e o surgimento de um novo tipo de dinâmica econômica urbana ao longo dos anos 1980 e 1990 é discutido. Meu argumento é de que essa nova dinâmica baseia-se, em grande medida, no crescimento e disseminação de sistemas de produção cultural-cognitivos. Em paralelo a essas mudanças ocorreram profundas transformações no espaço urbano e na vida social e muitas cidades empreenderam esforços para se 
consolidarem como centros culturais nacionais e internacionais. Esse argumento é o fundamento do que podemos chamar de hipótese da metrópole ressurgente. Os efeitos da globalização são considerados como de fundamental importância na gênese e geografia do ressurgimento urbano. Três dilemas políticos das cidades ressurgentes são destacados: sua fragmentação institucional interna; o fortalecimento de sua condição de agentes econômicos em escala global e a importância concomitante das formas coletivas de construção de vantagens competitivas localizadas; e a intensificação de sua desintegração e segmentação sociais.

Palavras-chave: economia cultural-cognitiva; globalização; espaço intraurbano; urbanização; governança urbana; teoria urbana.

RESURGENT METROPOLIS: ECONOMY, SOCIETY AND URBANIZATION IN AN INTERCONNECTED WORLD

Abstract: An urban problematic is identified by reference to the essential characteristics of cities as spatially polarized ensembles of human activity marked by high levels of internal symbiosis. The roots of the crisis of the classical industrial metropolis of the twentieth century are pinpointed, and the emergence of a new kind of urban economic dynamic over the $1980 \mathrm{~s}$ and $1990 \mathrm{~s}$ is discussed. I argue that this new dynamic is based in high degree upon the growth and spread of cognitive-cultural production systems. Along with these developments have come radical transformations of urban space and social life, as well as major efforts on the part of many cities to assert a role for themselves as national and international cultural centers. This argument is the basis of what we might call the resurgent metropolis hypothesis. The effects of globalization are shown to play a critical role in the genesis and geography of urban resurgence. Three major policy dilemmas of resurgent cities are highlighted, namely, their internal institutional fragmentation, their increasing character as economic agents on the world stage and the concomitant importance of collective approaches to the construction of localized competitive advantage, and their deepening social disintegration and segmentation.

Keywords: cognitive-cultural economy; globalization; intra-urban space; urbanization; urban governance; urban theory. 


\section{Bibliografia}

AMIN, A.; THRIFT, N. (2002) Cities: remaging the urban. Cambridge: Polity.

AMIN, S. (1973) Le développment inégal: essai sur les formations sociales du capitalisme périphérique. Paris: Les Éditions de Minuit.

ANGEL, D. P. (1991) High-technology agglomeration and the labor market: the case of Silicon Valley. Environment and Planning A, n. 23, p. $1501-16$.

BAGNASCO, A. (1977) Tre Italie: la problematica territoriale dello sviluppo italiano. Bolgna: Il Mulino.

BATT, R.; CHRISTOPHERSON, N.; JAARSVELD, D.V; RIGHTOR, N. (2001) Net working: work patterns and workforce policies for the new media industry. Washington DC: Economic Policy Institute.

BARTER, P. A.; BUNNEL, T.; MORSHIDI, S. (2002) Kuala Lampur metropolitan area: a globalizing city-region. Cities, n. 19, p. 357-70.

BATNITZKY, A.; DYER, S.; MCDOWELL, L. (2007) Division, segmentation and interpellation: the embodied labors of migrants workers in a Greater London hotel. Economic Geography, n. 81, p. 1-26.

BEAUREGARD, R. A. (2004) The resilience of US cities: decline and resurgence in the 20th century. In: Leverhulme International Symposium on the Resurgent City, London, p. 19-21.

BINNIE, J.; HOLLOWAY, J.; MILLINGTON, S.; YOUNG, C. (2006) Grounding cosmopolitan urbanism: approaches, practices and policies. In: . Cosmopolitan urbanism. London: Routledge.

BLAIR, H. (2001) You're only as good as your last iob: the labor process and labor market in the British film industry. Work Employment and Society, n.15, p. 149-69.

BLUESTONE, B.; HARRISON, B. (1982) The deindustrialization of America. New York: Basic Books.

BOUDREAU, J. A.; HAMEL, P. KEIL, R.; JOUVE, B. (2006) Comparing metropolitan governance: the cases of Montreal and Toronto. Progress in Planning, n.66, p.7-59.

BRENNER, Neil. (2004) Urban governance and the production of new state spaces in Western Europe. Review of International Political Economy, n.11, p.447-88.

BRITISH DEPARTMENT OF CULTURE. (2001) The creative industries mapping document. London. Disponível em: 
<www.culture.goc.uk/creative/mapping.html> Acesso em: 24/08/2008.

CAIRNCROSS, F. (1997) The death of distance: how the comunications revolution will change our lives. Boston: Harvard Business School Press.

CARNEY, J.; HUDSON, R.; LEWIS, J. (1980) Regions in crises: new perspective in European regional theory. New York: St Martin's Press.

CASTELLS, M. (1968) Y a-t-il une sociologie urbaine? Sociologie $d u$ Travail, n. 1, p. 72-90.

CHANG, T. (2000) Renaissance revisited: Singapore as a 'global city for the arts'. International Journal of Urban and Regional Research, n. 24, p. 818-31.

CHESHIRE, P.C. (2006) Resurgent cities, urban myths and policy hubris: what we need to know. Urban Studies, n. 43, p. 1231-46.

CORIAT, B. (1979) L'atelier et le chronometer: essai sur le Taylorisme, le Fordisme, et la production de masse. Paris: C. Bourgois.

DANIELS, P. W. (1995) The locational geography of advanced producers services in the United Kingdom. Progress in Planning, n. 43 (2-3), p. 12338.

DEAR, M. J. (2000) The postmodern condition. Oxford: Blackwell.

EMMANUEL, A. (1969) L'échange inégal. Paris: Maspéro.

ESSER, J.; HIRSCH, J. (1989) The crisis of Fordism and the dimension of a postfordist regional and urban structure. International Journal of Urban and Regional Research, n. 13, p. 417-37.

FLORIDA, R. (2004) Cities and creative class. London: Routledge.

FRÖBEL, F.; HEINRICHS, J.; KREYE, O. (1980) The new international division of labor. Cambridge: Cambridge University Press.

GAROFOLI, G. (eds). (2007) Development on the ground: clusters, networks and regions in emerging economies. London: Routledge.

GEREFFI, G. Global production systems and third world development. In: STALLINGS, B. (ed.). (1995) Global change, regional response: the new international context of development. Cambridge: Cambridge University Press.

GERTLER, M.S. (1988) The limits to flexibility: comments on the postfordist vision of production and its geography. Transactions of the Institute of British Geographers, n. 13, p. 419-31.

GLAESER, E.; GOTTLIEB, J. (1988) Urban resurgence and the consumer city. Urban Studies, n. 43, p. 1275-99. 
GLASMEIER, A.; MARKUSEN, A HALL, P. (1986) High tech America: the what, how, where and why of the sunrise industries. Boston: Allen and Unwin.

GOTHAM, K. F. (ed.). (2001) Critical perspectives on urban redevelopment. Amsterdam: JAI (Research in Urban Sociology).

GRABHER, G. (2004) Temporary architectures of learning: knowledge governance in project ecologies. Organization Studies, n. 25, p. 1491-514.

HALL, P. (2001) Global city-regions in the twenty-first century. In: SCOTT, A. J. (ed.). Global city-regions: trends, theory, policy. Oxford: Oxford University Press.

HARVEY, D. (1989) From managerialism to entrepreneurialism: the transformation in urban governance in late capitalism. Geografiska Annaler (Series B), n. 71, p. 3-17.

HIRSCHMAN, A.O. (1958) The strategy of economic development. New Haven: Yale University Press.

HONG KONG CENTRAL POLICY UNIT. (2003) Baseline study on Hong Kong's creative industries. Hong Kong, Centre for Cultural Policy Research, University of Hong Kong.

HUANG, M. T .Y. (2006) The cosmopolitan imaginary and flexible identities of global city-regions: articulating new cultural identities in Taipei and Shanghai. Inter-Asia Cultural Studies, n. 7, p. 472-91.

HYMAN, R. (1991) Plus ça change? The theory of production and the production of theory. In: POLLERT, A. (ed.) Farewell to flexibility? Oxford: Blackwell.

IAURIF. (2006) Les industries culturelles en Ile-de-France. Paris: Institut d'Aménagement et d'Urbanisme de la Région Ile-de-France.

JACOBS, J. (1969) The economy of cities. New York: Random House.

KRÄTKE, S.; TAYLOR, P. J. (2004) A world geography of global media cities. European Planning Studies, n.12, p. 459-77.

LEVY, F.; MURNANE, R. J. (2004) The new division of labor: how computers are creating the next job market. New York: Russel Sage Foundation.

LLOYD, R.; CLARK, T.N. The city as an entertainment machine. In:

MARKUSEN, A.; MEEGAN, R. (2006) The distinctive city: divergent patterns in growth, hierarchy and specialization. Urban Studies, n. 43, p. 1301-23. 
MASSEY, D.; MEEGAN, R. (1982) Anatomy of job loss: the how, why, where, and when of employment decline. London: Methuen.

MAYER, M. (2003) The onward sweep of social capital: causes and consequences for understanding cities, communities and urban movements. International Journal of Urban and Regional Research, n. 27, p. 110-31.

MOULIER BOUTANG, Y. (2007) Le capitalism cognitive: comprendre la nouvelle grand transformation et ses enjeux. Paris: Amsterdam.

MYRDAL, G. (1959) Economic theory and under-developed regions. London: Gerald Duckworth \& CO.

NEFF, G; WISSINGER, E.; ZUKIN, S. (2005) Entrepreneurial labor among cultural producers: cool jobs in hot industries. Social Semiotics, n. 15, p. 3007-34.

O'BRIEN, R. O. (1992) Global financial integration: the end of geography. London: Royal Institute of International Affairs.

O'CONNOR, J. (1998) Popular culture, cultural intermediares and urban regeneration. In: HALL, T.; HUBBARD, P. (eds.). The entrepreneurial city: geographies of politics, regime and representation. Chichester: John Wiley.

PERROUX, F. (1961) L'Economie $d u \quad X X^{e}$ siècle. Paris: Presses Universitaires de France.

PIORE, M.; SABEL, C. (1984) The second industrial divide: possibilities for prosperity. New York: Basic Books.

POLLERT, A. (1991) The orthodoxy of flexibility. In: . Farewell to flexibility? Oxford: Blackwell.

PRATT, A. C. (1997) The cultural industries production system: a case study of employment change in Britain, 1984-91. Environment and Planning A, n. 29, p. 1953-74.

PUTNAM, R. (2000) Bowling alone: the collapse and revival of American community. New York: Simon and Schuster.

RULLANI, E. (2000) Le capitalism cognitive: du déjà vu? Multitudes, n. 2, p. 87-94.

SASSEN, S. (1994) Cities in a world economy. Thousand Oask: Pine Forges Press.

SAYER, A. (1989) Postfordism in question. International Journal of Urban and Regional Research, n. 13, p. 666-95.

SCHMITZ, H. (1980) Regional systems and global chains. In: SCOTT, A. J.; SCOTT, A. J. The urban land nexus and the state. London: Pion. 
SCOTT, A. J. (1988a ) Metropolis: from the division of labor to urban form. Berkeley: University of California Press.

(1988b) New industrial spaces: flexible production $\overline{\text { organization }}$ and regional development in North America and Western Europe. London: Pion.

. (1998) Multimedia and digital visual effects: an emerging local labor market. Monthly Review, n. 121, p. 30-8.

SCOTT, D. H; KATZ, L. F; KEARNEY, M.S. (2006) The polarization of the US labor market. American Economic review, n.96, p. $1984-95$.

SCOTT, D. H; LEVY, F.; MURNANE, R.J. (2003) The skill content of recent technological change: an empirical exploration. Quartely Journal of Economics, n. 118, p. 1279 - 333.

SENNETT, R. (1998) The corrosion of character: the personal consequences of work in the new capitalism. New York: W.W. Norton.

SIMMEL, G. (1959) The metropolis and mental life. In: WOLFF, K. H. The sociology of George Simmel. New York: Free Press.

SMITH, N. (2002) New globalism, new urbanism: gentrification as global urban strategy. Antipode, n.34, p. 427-50.

SOJA, E. W. (2000) Postmetropolis: critical studies of cities and regions. Oxford: Blackwell.

STADTrat. Culture industries in Europe. Regional development concepts for private-sector cultural production and services. Ministry of Economy and Business, Technology and Transport and Ministry for Employment, Social Affairs and Urban Development, Culture and Sport of the State of North Rhine-Westphalia, Dusseldorf.

STORPER, M. (1997) The regional world: territorial development in a global economy. New York: Guilford Press.

STORPER, M.; VENABLES, A. J. (2004) Buzz: face-to-face contact and the urban economy. Journal of Economic Geography, n. 4, p. 351-70.

TAYLOR, P. J. (2005) Leading world cities: empirical evaluations of urban nodes in multiple networks. Urban Studies, n. 42, p. 1593-608.

MYKHENKO, V.; TUROK, I. (2006) The trajectories of European cities (1960-2005). Cities, n. 24, p. 165-82.

URSELL, G. (2000) Television production: issues of exploitation, commodification and subjectivity in UK television markets. Media, Culture and Society, n. 22, p. 805-25. 
VERCELLONE, C. (2007) From formal subsumption to general intellect: elements for a Marxist reading of the thesis of cognitive capitalism. Historical Materialism, n.15, p. 13-36.

YEOH, B. S. A. (2005) The global cultural city? Spatial Imagineering and politics in the (multi)cultural marketplace of South-East Asia. Urban Studies, n.42, p.945-58.

Data de submissão: 21/10/2014

Data de aprovação: 21/12/2014 